\title{
Identifying and managing incidents of minor theft within a service for individuals with intellectual disabilities
}

\author{
Grainne Tinney $^{1}$ | Martine Smith ${ }^{2}$ (D)
}

${ }^{1}$ Prosper Fingal, Skerries, Co. Dublin, Ireland ${ }^{2}$ Clinical Speech \& Language Studies, Trinity College, Dublin, 2, Ireland

\section{Correspondence}

Martine Smith, Clinical Speech \& Language Studies, Trinity College, 7-9 South Leinster Street, Dublin 2, Ireland.

Email: mmsmith@tcd.ie

\section{Accessible summary}

- Our service received complaints about some service users who were taking items from local shops without paying for them.

- We surveyed families to see how common this problem was and what families had done to try to prevent it happening again.

- One in three families who responded said a family member had taken something from home or a shop without paying for it; often this happened when changes were occurring in the home.

- The service has started to work with families, service users and the local community, to ensure that service users are well supported and that people respond consistently to any minor thefts that occur.

\section{Abstract}

Background: Models of service delivery for adults with an intellectual disability in Ireland increasingly focus on delivering services within local communities. Preparation for this transition often focuses on practical skills. Our service received complaints about unacceptable behaviour (i.e., shoplifting), by some service users. Although such behaviours are relatively common in the general population, we found little research on this topic related to individuals with intellectual disabilities.

Method: The Speech and Language Therapy Department surveyed families of individuals attending the service to explore the prevalence of concerns about such behaviours and any actions families had taken.

Results: Over 34\% of families who responded reported at least one incident of stealing. Such behaviours occurred within the home and in the community. Families had attempted a range of strategies to eliminate the behaviour, most often invoking a negative consequence.

Conclusion: The combination of (a) changed opportunities arising from new service structures and (b) potentially reduced self-control and/or immature self-regulation, along with (c) inconsistent responses from the environment, forms a triad of influences that may contribute to the risk of stealing for some individuals with intellectual disability. Strategies adopted by the organisation to address this issue are outlined.

\section{KEYWORDS}

community care, family support, health and social care policy and practice, independent living, intellectual disability 


\section{1 | INTRODUCTION}

Among the many aspects of development that emerge across childhood, learning socially acceptable norms of behaviour is critical. Norms for behaviour can be classified in many ways. Moral norms concern the welfare and rights of others, while norms related more to consequences for the actor or agent may be termed prudential norms. In early childhood, particular importance may be placed on pragmatic norms, those behaviours that have undesirable practical consequences for parents (e.g., a messy table; Dahl \& Campos, 2013). In interactions with their children, parents explicitly draw attention to desired norms of behaviour and the consequences of violating these norms from a very early age, so that by the age of 3 years, children seem to be able to draw distinctions between domains of norms (moral, prudential and pragmatic; Killen \& Smetana, 2008; Smetana et al., 2012) and consider violations of moral norms more negatively than other norm violations (Tisak, 1993).

The act of stealing constitutes a clear violation of moral norms and may have consequences that also violate prudential norms-the consequences of getting caught may be transient and unpleasant but may also extend to financial loss and loss of liberty. Nonetheless, stealing is relatively common (Grant, Odlaug, Lust, \& Christenson, 2016). One study (Blanco et al., 2008) reported that just over $11 \%$ of adults admitted to having shoplifted at some stage in their lives. Stealing generally seems to emerge in childhood or adolescence (Moncher \& Miller, 1999). One study of 3,999 high school students (Grant, Potenza, Krishnan-Sarin, Cavallo, \& Desai, 2011) found that just over $15 \%$ had stolen at some point.

The causes leading to stealing behaviours are complex. Stealing seems more likely to occur in males and may be linked to an orientation to risk-taking behaviours and positive peer affirmation and social acceptability. There is some evidence (Ingamells \& Epston, 2013) that the behaviour may increase during episodes of stress or depression. Not all adolescents steal, and many of those who do engage only in one-off incidents (Grant et al., 2016). Across childhood and adolescence, individuals come to recognise the moral norm (i.e., it is not acceptable to take things that belong to others) and develop the ability to suppress the impulse to have and own a desired object.

The concept of stealing is itself complex: simply taking something that is not one's own is not necessarily theft. The colleague who crosses the room and takes a stapler from another desk will probably not be judged to be "stealing" the stapler, although persistence of the behaviour may invoke negative reactions. Accidentally acquiring someone else's suitcase from a luggage belt is understood to involve taking, but not stealing. Stealing involves intentionally taking something without permission, usually in secrecy. The desire to ensure secrecy may stem from recognition that the behaviour is unacceptable (i.e., violates moral norms) and/ or from motivation to avoid unpleasant consequences-exposure and punishment (Langdon, Clare, \& Murphy, 2011). Recognising the distinction between taking and stealing, and learning to predict the consequences of being caught, as well as possible strategies to avoid those consequences, are all insights that emerge over the childhood and adolescent years, largely through experiences. Children and young people are often explicitly taught they must develop self-control and inhibit their desire to have something if it is not rightfully theirs, if they do not have permission to have it, or if they do not have funds to purchase it.

\section{1 | Self-control and self-regulation}

The central tenet of Gottfredson and Hirschi's (1990) Self-control theory is that low self-control (characterised by a tendency towards impulsivity, short-sightedness and risk-taking behaviours) inhibits the ability to refrain from deviant behaviours when the opportunity to engage in such behaviours arises. Children's levels of self-control are stabilised by early- to mid-adolescence (Vazsonyi \& Jiskrova, 2018). However, their awareness of moral norms appears at a much younger age. They have been demonstrated to show understanding of property rights and violations of those rights through either damage or stealing as young as two, although concern about property rights of others (rather than their own rights) seems to emerge around the age of three (e.g., Rossano, Rakoczy, \& Tomasello, 2011). Inhibiting the temptation to steal requires understanding the property rights of others, but also relies on self-control. Both of these developments are underpinned by cognitive development and opportunities to learn through experiences. For young people and adults with intellectual disabilities, both the cognitive underpinnings and the learning opportunities needed to develop the moral norms and the self-control may be fragile.

Similarly, self-regulation implies the ability to manage one's own behaviour in order to achieve desired goals (Bandura, 1986). Selfregulation is complex, comprising many sub-functions, but at a minimum it incorporates an awareness of self, a belief that the self is an active agent and an understanding of one's capabilities (Cuskelly, Zhang, \& Gilmore, 1998). The ability to self-regulate emerges developmentally. Kopp (1991) proposed that it begins with the parent taking full responsibility for a child's behaviour and ends with a child assuming that responsibility, but that this shift takes a number of years and many experiences.

\subsection{Shifting service structures}

Over the past decades, new policies promoting integration and inclusion (Bigby, Bould, \& Beadle-Brown, 2018) under the mantra of doing ordinary things in ordinary places (Health Services Executive, Ireland, 2012; hse.ie/eng/services/list/4/disability/newdirections/) have required a transition away from structured and highly supported day service provision for adults with disabilities to community-based, activity-focused engagement. This shift has created a new reliance on informal community-based supports for learning and adaptation-supports from neighbours, shopkeepers, bus drivers and friends. In Ireland, this transition has happened rapidly, often in the absence of explicit coping strategies to deal with either the new freedoms of community inclusion and/or the demands of independence. 
Interventions to support independence for adults with intellectual disabilities tend to emphasise independence in activities that are essential to daily life, such as independent travel. Learning how to cope with using public transport is easily translated into a clearly defined intervention plan, with incremental learning. Learning how to cope with the external context in which that public transport operates, the multitude of unpredictable factors that people meet as they make their way to their local bus stop, represents a far greater challenge for service providers and for individuals with intellectual disability. The variability and the individual nature of these factors exacerbate the challenge. Individuals must learn when and how to interact with an unpredictable range of communication partners as they make their way to public transport. Along that path, they must inhibit impulses to enter businesses or shops they pass, even though they may observe others going in and buying desirable items.

Perhaps as a consequence of these hidden challenges in supporting independence and inclusion, unexpected problems can surface. The service in which the first author is based provides day, residential and respite services to adults with mild-to-moderate intellectual disabilities. The service strives to implement New Directions (HSE, 2012) policy and person-centred planning, by supporting adults with disabilities to optimise their independence and to access what they themselves view as important in their community alongside other members of the community (i.e., in classes, jobs, leisure activities). As a consequence of this shift in service focus, adults now access small, locally based day services rather than the larger congregated settings that previously characterised service provision.

The first author became aware that a number of staff and family members of adults attending the service were expressing concerns about apparently new and inappropriate behaviours. One particularly salient issue is related to incidents of minor theft. These concerns came to a head when the service was notified by a local shop to say that a number of young adult service users were stealing items. This was a new issue for the service, and there was no existing plan or policy for managing these concerns. In order to plan an intervention, it became clear that further information about the behaviours and the extent to which they were present across the service user community was needed.

\section{3 | Research questions}

The research described here was initiated to explore the following questions: (a) How common are reports of shoplifting or other minor thefts for service users? and (b) What actions have families taken to address any incidents that have arisen, and to what effect?

\section{2 | METHOD}

A short questionnaire survey was undertaken by the Speech and Language Therapy Department to gather data from across the service. Ethical approval was granted by the ethics committee of the first author's organisation. The questionnaire focused on participant experiences and the opportunities and risks emerging in the context of increased participation of service users in the community. These risks included those associated with policies to support community integration and the consequent new experiences in independence, choice and financial freedom for service users.

\section{1 | Participants}

All parents/carers of service users within the organisation were invited to participate in the research and to complete the questionnaire. Service users within this organisation are adults who have a diagnosis of mild-moderate intellectual disability.

\subsection{Materials}

The questionnaire consisted of 13 questions (see Appendix S1 for full questionnaire). Initial questions concerned biographical information (e.g., age and disability) and whether or not stealing behaviour had occurred. Further questions probed whether sons/daughters had access to their own money and opportunities to shop independently. If stealing behaviour was reported, participants were asked whether a significant life event had occurred at the time the stealing behaviour was noticed. The final question asked parents/carers what they had done to manage the behaviour. Participants were presented with a list of possible ways of managing the behaviour (e.g., insisting that the goods be returned or paid for, seeking support from day service or clinical team) and were also asked for any other management option they had considered or undertaken. Participants returned the questionnaires either by mail or in person to the service base most convenient to them. The data that support the findings of this study are available on request from the first author. The data are not publicly available due to privacy or ethical restrictions.

\section{3 | RESULTS}

Of the 146 questionnaires distributed, 47 were returned, a response rate of $32 \%$. Most questionnaires were completed by mothers of the service users (72\%). All service users for whom questionnaires were returned were described as having a moderate level of intellectual disability. These service users ranged in age from mid-20s to 50 s, and the majority (98\%) lived at home with parent/s and or other family members. From the questionnaires returned, two-thirds of the respondents ( $n=31,66 \%$ ) reported stealing had not arisen as an issue. The remaining 16 respondents reported at least one incident of stealing. Data from these 16 questionnaires are described further below.

The age profiles of individuals for whom stealing was reported did not differ from individuals for whom no concerns had been raised. Of the 16 service users who were reported to have engaged in at least one act of stealing, 12 (75\%) had an additional diagnosis of Down syndrome. By contrast, the proportion of individuals with an additional diagnosis of Down syndrome in the respondents for whom stealing was not reported as a concern was $43 \%$. Overall 
within the service, individuals with Down syndrome account for $49 \%$ of service users.

Most parents did not specify whether or not stealing had occurred repeatedly, although four noted it had occurred only once. One of these parents stated that, to her knowledge, it had happened on only one occasion. Her son, (R), is a man with a moderate intellectual disability and a diagnosis of Down syndrome. He has access to money weekly and travels independently to his day service, shops, cinemas and restaurants. His mother reported that he had stolen sweets when he was 17 years old from a local shop. A friend had witnessed him taking the sweets. R's mother intervened and spoke to him about the theft. She also talked to the shopkeeper and his service key worker. She asked the local Garda (police officer) to speak to him. She recalled that $\mathrm{R}$ did not see any problem with taking the sweets, stating, "it is only a bar of chocolate". Although his mother explained that it was wrong to take even a bar of chocolate, she felt the Garda intervention helped prevent it happening again.

The responses indicated that stealing happened in many different places. One parent reported that thefts only occurred in the home, six reported they occurred only in the community, while nine reported that incidents had occurred across both contexts. Most usually, money was stolen from home, while snacks and drinks were commonly stolen from shops, often when service users were not with parents or another adult. For example, $\mathrm{L}$ is a woman in her fifties. She is given approximately five Euro a day for spending. She goes independently to the local shop. Her sister reported that $L$ had taken food items and stationary from the local shops. When she was on a work experience, she also took money from the work experience site. L's sister reported that these incidents happened when $L$ was unsupervised. A neighbour had witnessed $L$ taking the items and contacted her sister. L's sister talked to the shopkeeper, made $L$ return the items and told her not to do it again. She also spoke to L's key worker.

When parents/carers discovered these behaviours were taking place, they attempted many different interventions to prevent a recurrence. The main strategies they reported using were (a) talking to their son/daughter and telling them not to do it again ( $n=15,94 \%)$, (b) insisting that items be returned $(n=9,56 \%)$ and (c) talking to the key worker for support ( $n=10,62 \%$ ). Some parents consulted other team members, including the psychologist, the social worker, the speech and language therapist and the centre manager. Four of the parents (25\%) asked a police officer to speak to their son or daughter in person, and some also changed where they shopped, to avoid further temptation or embarrassment.

Parents and carers gave various reasons for why they thought these behaviours happened. Some thought that their son/daughters had no understanding of the consequences; others thought that an opportunity to steal presented itself and could not be resisted, while three respondents reported that a significant life event was occurring at the time the stealing behaviour had come to attention. The story of $F$ provides one such example. $F$ is in her late twenties and has an additional diagnosis of Down syndrome. $\mathrm{F}$ is given money by her parents for outings, food and other items. F travels independently to and from her day service, as well as to shops and to the cinema. F's family reported that $F$ has taken money from her parents' wallets, as well as drinks, sweets, makeup, jewellery and CDs from shops. F's mother reported that at the time these incidents occurred, there was a lot of change in the family. There was a family bereavement, F's sister was moving out, friends were moving on from the service, and her mother was returning to work for the first time in many years. F's mother attempted to address the issue by seeking support from F's day service, by talking directly to the shop owners and by returning items where possible. However, she was unsure how successful these interventions were in eliminating the behaviours.

In sum, over one-third of families who returned questionnaires reported at least one incident of stealing by a service user family member. Those about whom concerns had been raised did not seem to differ in age from those where stealing was not reported, but a surprisingly large proportion of those who had at least one incident of stealing had an additional diagnosis of Down syndrome. Incidents of stealing took place in the home, but more commonly in the community. Parents had attempted a range of interventions to prevent recurrence of the behaviour but with inconsistent reports of success.

\section{DISCUSSION}

Even though this was a small-scale study, the responses to the questionnaires revealed that the behaviour of shoplifting was significant within the service. There may be many explanations for why this behaviour has emerged at this point. One may be the shift in service provision. Services are now community-based, and so the opportunities to engage in shoplifting are greatly increased. Such opportunities are also more diverse, as service users navigate multiple different microcommunities (e.g., transport, transit to and from transport locations, shops and work experiences). The adults who are now presented with these opportunities may have had little time to prepare for the range of challenges these new structures represent. Practical skills are a core focus of preparing to work within the community. The more subtle nuances of moral norms may not be as prominent in preparation plans.

The historically limited opportunities offered to adults with intellectual disability to embed into the community may also have an influence on the expectations of others in the community and their responses to infringements in socially acceptable behaviours (Simpson \& Hogg, 2001). For example, many retail staff may have had few encounters with individuals with intellectual disability, and even fewer experiences of having to challenge them. Inappropriate behaviour may be excused on the presumption that an individual does not fully understand the situation or the rules. Therefore, relative to their peers without disabilities, the learning opportunities that are afforded to those with an intellectual disability may not be as readily available and the consequences of inappropriate actions may not be as consistently applied or experienced.

Given what may have been limited life opportunities to engage independently in the community until adulthood, many adults with intellectual disability may also have had few opportunities or little 
need to learn to resist or control an impulse to take something they want. The desire for food or drink items may be particularly difficult to resist. Concerns are frequently raised about overall health measures and weight control in individuals with intellectual disability (e.g., McGuire, Daly, \& Smyth, 2007). Analysis of the most recent wave of longitudinal data from the national TILDA study (McCarron, Haigh, \& McCallion, 2017) reported that $79.7 \%$ of adults with intellectual disability were overweight or obese. Those most at risk seem to be those with a mild-moderate level of intellectual disability-precisely those individuals who are most likely to be functioning relatively independently within the community.

Concerns about health implications of weight gain may result in family members' attempting to ration sugary foods and snacks. As a consequence, individuals with intellectual disability may come to value such items even more highly and seek to procure them secretly, knowing that they will face disapproval if they consume them openly. It is also possible that the role of these foods as treats in childhood may have persisted, without an associated increase in awareness of their potential negative effects.

Together, the combination of (a) changed opportunities and temptations and (b) potentially reduced self-control and/or immature selfregulation, along with (c) inconsistent responses from others within the environment, may form a triad of influences that contribute to the risk of stealing for some individuals with intellectual disability. A catalyst, such as significant changes within the home environment, may trigger the onset of the behaviour, as has been found with children who do not have a disability (Ingamells \& Epston, 2013).

The triad of influences outlined above may impact individuals differently, suggesting that interventions to address the behaviours may also need to be multi-faceted. In fact, the interventions described by the parents focused primarily on implementing a negative consequence. Most often, this involved discussions about not engaging in the behaviour again, sometimes pulling in authority figures to add weight to the discussion. These interventions are characterised by Ingamells and Epston (2013) as focusing on changing the person, rather than the problem. Many of these interventions met with limited success in the current study, similar to other studies of young people without disabilities, where behavioural approaches have been found to have limited success in reducing stealing (e.g., Hinshaw, 2005; Venning, Blampied, \& France, 2003).

One approach trialled within the service has focused on the two dimensions where most change can likely be achieved: the opportunities presented and the responses from those within the community. This approach aligns with what Ingamells and Epston (2013) characterise as focusing on the problem (i.e., the stealing) rather than the person. One intervention addressed the issue, community responses, through working with local shop owners to raise awareness of the risk factors surrounding the behaviour for individual service users. Collaboratively, the Speech and Language Therapy Department and the relevant shop owners developed scripts to support staff to engage pro-actively and pre-empt the occurrence of any shoplifting incident. For example, for some service users the script involved reminding the person to check they have their wallet available and offering to hold the item until they have a chance to go and retrieve their money. For one individual, the strategy focused on changing opportunities by ensuring that the service user called to the service to collect money before heading to local shops.

Further evaluation is needed to determine the effectiveness of the range of strategies that have been implemented. However, from these initial attempts, a number of points have become clear. One is that the service itself has had to become more aware of the potential risk of stealing behaviours and more proactive in identifying the need for intervention. A second is the importance of embedding interventions in the community settings in which the risk presents. Extending the focus of intervention away from the service user to the broader context of the opportunities available and the response from the environment has shifted responsibility for managing the behaviour into a wider sphere. It has changed the emphasis from the person to the problem and the social context within which the problem manifests. In our experience, imposing negative consequences "after the fact" has limited impact on changing target behaviours for the adults supported within our service. Approaches that instead focus on influencing the environment and its response to those behaviours offer greater potential for meaningful change.

We are at the early stages of working to address these complex issues. The available literature on this topic is relatively sparse, in itself somewhat surprising given the relatively high proportion of respondents in this study who had experience of at least one incident of stealing and the consistent reports of over-representation of individuals with intellectual disabilities in the criminal justice systems of many jurisdictions (Cockram, 2005; Lindsay, Hastings, \& Beech, 2011). At least one study of adolescents found that although, for the group as a whole, the presence of mild-moderate intellectual disability was associated with increased rates of police contact, there was no difference in self-reported shoplifting for this group relative to peers without disabilities (Emerson \& Halpin, 2013).

We were particularly surprised at the relative over-representation of the presence of an additional diagnosis of Down syndrome in the group for whom stealing had been reported. It is possible that the small sample accounts for this apparent anomaly and additional research would be needed to evaluate this further.

\section{1 | Clinical implications}

The clinical implications of this study within our own service have highlighted the importance of addressing these behaviours through education and training for the community, establishing collaborative links and working in partnerships with community stakeholders. This approach has involved adopting a supportive rather than a punitive approach. Providing effective support has necessitated working closely with staff, ensuring they understand the risks and the importance of pre-empting risk with positive strategies. The ultimate goal is to support service users to make sensible decisions. Achieving this stage involves recognising the complexity of offering greater independence and empowering service users to safely navigate potentially stormy seas as they embrace greater autonomy and independence. 


\section{5 | CONCLUSION}

The data reported here are drawn from a small-scale survey and so represent an initial step in exploring this issue. The implications that can be drawn are limited by the scale of the research and by its context-a specific service in a changing set of structures. Nonetheless, the data highlight the potential complexity of the problem, as well as the importance of identifying hidden challenges implicit in extending the range of opportunities offered to adults with disabilities within their communities, to ensure that these risks form part of the planning process that underpins effective participation within those communities.

\section{DATA AVAILABILITY STATEMENT}

The data that support the findings of this study are available on request from the first author (grainnetinney@prosperfinal.ie). The data are not publicly available due to privacy or ethical restrictions.

\section{ORCID}

Martine Smith (iD https://orcid.org/0000-0003-2122-5607

\section{REFERENCES}

Bandura, A. (1986). Social foundations of thought and action: A social cognitive theory. Englewood Cliffs, NJ: Prentice-Hall.

Bigby, C., Bould, E., \& Beadle-Brown, J. (2018). Comparing costs and outcomes of supported living with group homes in Australia. Journal of Intellectual and Developmental Disability, 3, 297-307. https://doi. org/10.3109/13668250.2017.1299117

Blanco, C., Grant, J. E., Petry, N. M., Simpson, H. B., Alegria, A., Liu, S. M., Hasin, D. (2008). Prevalence and correlates of shoplifting in the United States: Results from the National Epidemiologic Survey on Alcohol and Related Conditions (NESAEC). American Journal of Psychiatry, 165, 905-913.

Cockram, J. (2005). Careers of offenders with an intellectual disability: The probabilities of re-arrest. Journal of Intellectual Disability Research, 49, 525-536.

Cuskelly, M., Zhang, A., \& Gilmore, L. (1998). The importance of self-regulation in young children with Down syndrome. International Journal of Disability, Development \& Education, 45, 331-342.

Dahl, A., \& Campos, J. (2013). Domain differences in early social interactions. Child Development, 84, 817-825.

Emerson, E., \& Halpin, S. (2013). Anti-social behaviour and police contact among 13-to 15-year old English adolescents with and without mild/moderate intellectual disability. Journal of Applied Research in Intellectual Disabilities, 26, 362-369.

Gottfredson, M. R., \& Hirschi, T. (1990). A general theory of crime. Stanford, CA: Stanford University Press.

Grant, J. E., Odlaug, B. L., Lust, K., \& Christenson, G. (2016). Characteristics and correlates of stealing in college students. Criminal Behaviour and Mental Health, 26, 101-109.

Grant, J. E., Potenza, M. N., Krishnan-Sarin, S., Cavallo, D. A., \& Desai, R. A. (2011). Stealing among high school students: Prevalence and clinical correlates. Journal of the American Academy of Psychiatry and the Law, 39, 44-52.

Health Services Executive, Ireland (2012). New directions: Personal support services for adults with disabilities; Review of HSE day services and implementation plan 2012-2016. Retrieved from hse.ie/eng/services/ list/4/disability/newdirections/
Hinshaw, S. P. (2005). Objective assessment of covert anti-social behaviour: Predictive validity and ethical considerations. Ethics and Behavior, 15, 259-269.

Ingamells, K., \& Epston, D. (2013). A family and community approach to stealing. Journal of Systemic Therapies, 32, 43-55.

Killen, M., \& Smetana, J. (2008). Moral judgment and moral neuroscience: Intersections, definitions and issues. Child Development Perspectives, 2, 1-6.

Kopp, C. (1991). Young children's progression to self-regulation. In M. Bullock (Ed.), The development of intentional action: Cognitive, motivational and interactive processes, Vol. 22. Contribution to human development (pp. 38-54). Basel, Switzerland: Karger.

Langdon, P., Clare, I. C., \& Murphy, G. H. (2011). Moral reasoning theory and illegal behaviour by adults with intellectual disabilities. Psychology, Crime \& Law, 17, 101-115.

Lindsay, W., Hastings, R., \& Beech, A. (2011). Forensic research in offenders with intellectual and developmental disabilities, 2: Assessment and treatment. Psychology, Crime \& Law, 17, 97-100.

McCarron, M., Haigh, M., \& McCallion, P. (Eds) (2017). Health, wellbeing and social inclusion: Ageing with an Intellectual Disability in Ireland. Evidence from the first ten years of the Intellectual Disability supplement to the Irish Longitudinal Study on Ageing (IDS-TILDA). Retrieved from www.idstilda.tcd.ie

McGuire, B. E., Daly, P., \& Smyth, F. (2007). Lifestyle and health behaviours of adults with an intellectual disability. Journal of Intellectual Disability Research, 51, 497-510. https://doi. org/10.1111/j.1365-2788.2006.00915.x

Moncher, F. J., \& Miller, G. E. (1999). Nondelinquent youths' stealing behavior and their perceptions of parents, school, and peers. Adolescence, 34, 577-591.

Rossano, F., Rakoczy, H., \& Tomasello, M. (2011). Young children's understanding of violations of property rights. Cognition, 121, 219-227. https://doi.org/10.1016/j.cognition.2011.06.007

Simpson, M. K., \& Hogg, J. (2001). Patterns of offending among people with intellectual disability: A systematic review. Part 1: Methodology and prevalence data. Journal of Intellectual Disability Research, 45, 384-396.

Smetana, J., Rote, W. M., Jambon, M., Tasopoulous-Chan, M., Villalobos, M., \& Comer, J. (2012). Developmental changes and individual differences in young children's moral judgments. Child Development, 83, 683-696.

Tisak, M. S. (1993). Preschool children's judgments of moral and personal events involving physical harm and property damage. Merrill-Palmer Quarterly, 39, 374-390.

Vazsonyi, A., \& Jiskrova, G. (2018). On the development of self-control and deviance from preschool to middle adolescence. Journal of Criminal Justice, 56, 60-69.

Venning, H. B., Blampied, M., \& France, K. (2003). Effectiveness of a standard parenting-skills program in reducing stealing and lying in two boys. Child \& Family Behaviour Therapy, 25, 31-44.

\section{SUPPORTING INFORMATION}

Additional supporting information may be found online in the Supporting Information section at the end of the article.

How to cite this article: Tinney G, Smith M. Identifying and managing incidents of minor theft within a service for individuals with intellectual disabilities. Br J Learn Disabil. 2019;00:1-6. https://doi.org/10.1111/bld.12288 